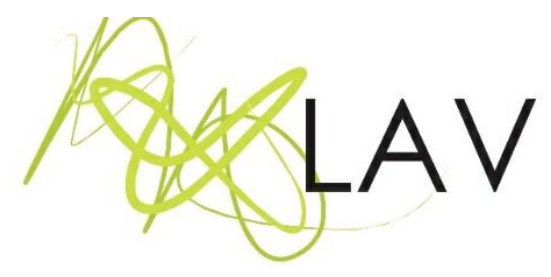

\title{
Coisas inventadas: montagem e edição em um cineclube escolar
}

Invented things: editing and montage in a school cinema club

Sandra Regina de Freitas Amarali Prefeitura Municipal de Campinas

Mauro Antonio Guarii Prefeitura Municipal de Campinas

Wenceslao Machado de Oliveira Jriii Universidade Estadual de Campinas

\section{Resumo}

Este artigo demonstra parte da experiência de professoras e professores da educação infantil com montagem e edição de pequenos filmes realizados em escolas da periferia de Campinas - SP. Essas experiências expressam um traçado que emergiu na pesquisa cartográfica, desenvolvida no Projeto Lugar-escola e cinema, e levaram a ensaiar a perspectiva da montagem como mestre ignorante de uma pedagogia do cinema. Inicialmente, distingue-se os conceitos de montagem e edição, devido às singularidades do contexto escolar e do modo como o cinema é ali produzido. Em seguida, relata-se e reflete-se acerca de alguns processos de criação individual e coletiva de filmes em que montagem e edição operam distintamente nas negociações entre docentes-cineastas e no aprendizado com e do cinema. Sendo esses processos tão múltiplos quanto intuitivos, o artigo relata como a intuição aliada ao conhecimento técnico levou a certo tipo de montagem, na qual a proliferação de sentidos e a confiança no espectador atuam de maneira decisiva em nossa experiência de fazer-ver-conversar em um cineclube escolar.

Palavras-chave: cinema, educação infantil, montagem, formação de professores.

\begin{abstract}
The present article is based on the experience of child education teachers in montage of short films carried out in schools in the outskirts of Campinas-SP. These experiences express a path that emerged in the cartographic research developed in the project Lugarescola e cinema (Place-school and cinema), and led us to rehearse the perspective of montage as ignorant schoolmaster of a pedagogy of cinema. The article begins by indicating the need to distinguish the concepts of editing and montage, due to the singularities of the school context and the way cinema is produced there. Then, it reports and reflects on processes of individual and collective film creation, where montage and editing act distinctly in negotiations between teachers-filmmakers and in learning from and with cinema. Since these processes are as multiple as they are intuitive, the article reports in what way intuition combined with technical knowledge led to a certain type of montage, where the spread of senses and confidence in the viewer play a decisive role in our experience of making-seeing-talking about films in a school cine club.
\end{abstract}

Keywords: cinema, child education, montage, teacher training. 


\section{Introdução}

Desde 2017, desenvolvemos o Cineclube Regente/Cha nas escolas de Educação Infantil CEI Regente Feijó e CEI Cha II Sun. As duas escolas estão localizadas na periferia da cidade de Campinas, interior do Estado de São Paulo. Podemos dizer que as escolas são gêmeas, pois compartem a mesma equipe gestora e encontram-se no mesmo terreno, em uma área de aproximadamente oito mil metros quadrados, composta de dois prédios anexos, e muita área verde nos parques que ficam nas extremidades, onde há grandes jequitibás e outras árvores da mata atlântica, bem como horta, borboletário, galinheiro, tanque de areia e brinquedos variados (Figuras 1 e 2 ).

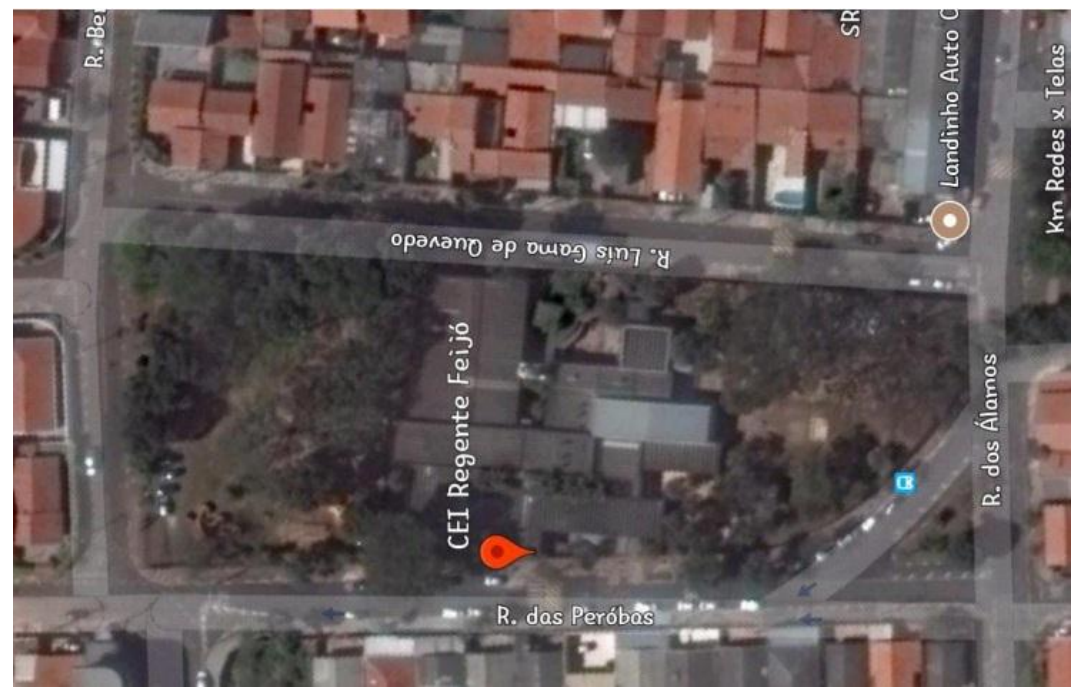

Figura 1: Imagem do quarteirão onde se situam as duas escolas Fonte: Google Earth

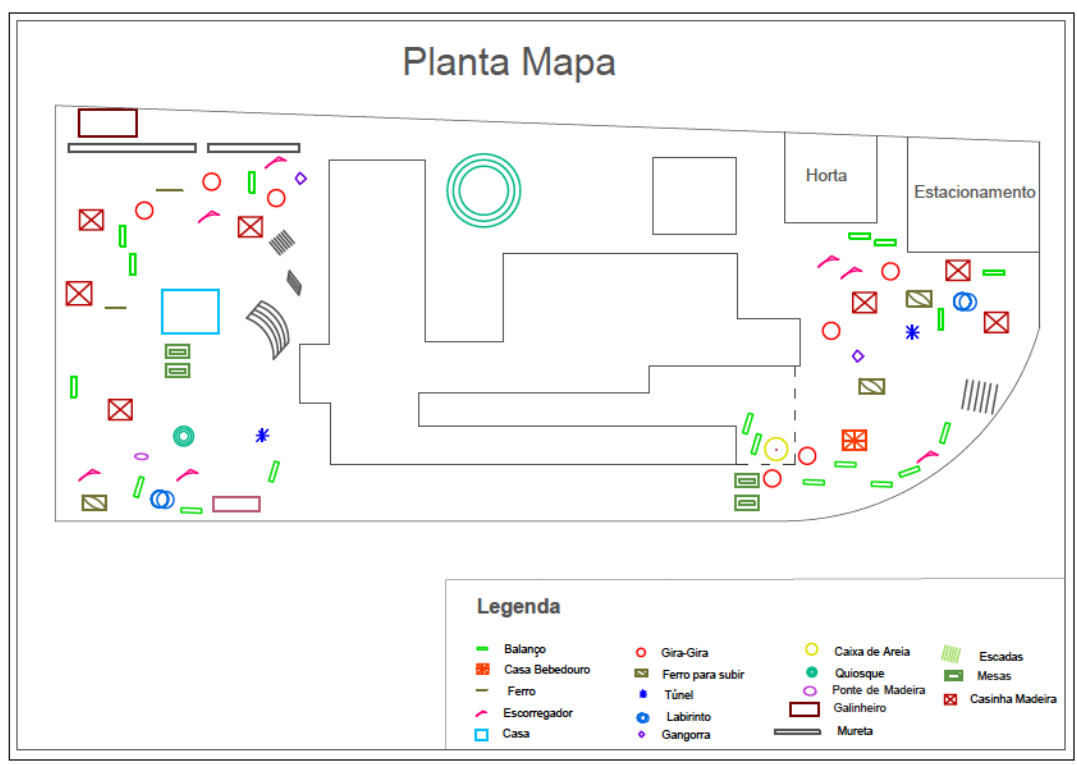

Figura 2: Planta-mapa do lugar-escola Elaboração: Stella Rodrigues (Bolsista SAE-Unicamp) Fonte: Acervo do Projeto Lugar-escola e cinema 
O cinema chegou nessas escolas no final de 2016 por meio de oficinas oferecidas pelo Programa Cinema e Educação ${ }^{1}$, da Secretaria Municipal de Educação de Campinas, em parceria com o Laboratório de Estudos Audiovisuais-OLHO/Unicamp. Essas oficinas foram realizadas com as professoras, os professores, as monitoras e os monitores das duas escolas e, ao final, um grupo se constituiu criando o Cineclube Regente/Cha, no qual se inseriu o Projeto Lugar-escola e cinema: afetos e metamorfoses mútuas², mesclando extensão e pesquisa através do método da cartografia.

O método cartográfico trata-se, concisamente, de um método de pesquisaintervenção, baseado nos pensamentos de Gilles Deleuze e Félix Guattari (1995) e de Fernand Deligny (2015), que tem a intenção de acompanhar e mapear processos inventivos e processos de produção de subjetividade com forte relação com o contexto espacial - lugar - onde esses processos se dão. No referido Projeto, apoiamo-nos especialmente nas pistas para o método cartográfico presentes em Escóssia, Kastrup e Passos (2015) e Passos, Kastrup e Tedesco (2014), bem como em outras obras desses autores.

Em um de seus artigos, eles apontam que

a cartografia é um método de investigação que não busca desvelar o que já estaria dado como natureza ou realidade preexistente. Partimos do pressuposto de que o ato de conhecer é criador da realidade, [...] [conhecer] é intervir sobre a realidade. É transformá-la para conhecê-la. Há uma dimensão da realidade em que ela se apresenta como processo de criação, como poiesis, o que faz com que, em um mesmo movimento, conhecê-la seja participar de seu processo de construção (PASSOS; KASTRUP, 2013, p. 264).

Nesse sentido, pode-se dizer que acompanhar os diversos processos de criação cinematográfica junto ao cineclube da escola é também um processo de tornar-se professor(a), de re-inventar-se como professor(a), na medida em que a capacidade de autoria lhe é conferida de maneira intensa, tendo em vista que o acompanhamento cartográfico não implica em capacitação, mas em apoio e suporte para aquilo que emergir dos próprios processos de criação - autoria! - com o cinema na escola. Este artigo, por exemplo, estabelece um traçado no mapa do encontro entre cinema e escola de educação infantil a partir das experiências com montagem e edição de vários filmes. $O$ acompanhamento tem se realizado a partir de estratégias diversas, tais como reuniões

\footnotetext{
${ }^{1}$ Ver: <http://educacaoconectada.campinas.sp.gov.br/programa-cinema-educacao>.

2 Projeto financiado pela Fapesp [processo 2018/09258-4] com seis bolsistas/profissionais da educação infantil, entre eles dois dos autores desse artigo, configurando-se como guarda-chuva para as várias experimentações e pesquisas realizadas na escola.
} 
coletivas semanais, realização de filmes coletivos, trocas constantes em grupo de whatsapp, escritas de registros reflexivos e cartas sobre as experiências com cinema ${ }^{3}$.

Em suma, este artigo realiza uma espécie de montagem textual de nossos estudos e reflexões coletivas a partir de fragmentos de registros escritos sobre os processos de montagem e edição cinematográfica ao longo do primeiro ano do Projeto.

\section{Um conceito de montagem (e edição) para dizer de nosso modo de fazer cinema}

Iniciamos as atividades do Cineclube Regente/Cha a partir da exibição de curtas nacionais e da produção de filmes na escola que, posteriormente, foram exibidos, em uma Mostra de cinema para as crianças, educadores e famílias. Desde então, seguimos realizando essas atividades de ver-conversar-produzir cinema e filmes de curta metragem. Considerando que a produção de filmes pressupõe planejamento, filmagem, montagem e edição, neste texto, iremos narrar, descrever e refletir um pouco do percurso e desafios da montagem e da edição de pequenos filmes no âmbito do Cineclube.

Tendo em vista as especificidades desse cinema que tem emergido nas duas escolas e para melhor lidar com os gestos cinematográficos de montar e editar, decidimos encontrar para eles sentidos que nos auxiliem a pensar não qualquer cinema, mas sim o cinema que temos produzido. Os sentidos de montagem que aqui trazemos nos auxiliam também a refletir sobre os processos de aprendizagem do e com o cinema que têm sido engendrados nos professores-cineastas, apostando no processo de montagem - aí incluída a edição - como uma pedagogia do cinema, lembrando que "pensar uma pedagogia é interrogar constantemente uma relação entre pedagogo e aprendiz - esse espectador/estudante de cinema" (MIGLIORIN; BARROSO, 2019, p. 93). Nessa pedagogia em que a montagem faz o papel de "mestre ignorante" (RANCIÈRE, 2015), o espectador é convidado a participar da criação de sentidos para o filme justamente onde este parece ganhar ou perder os sentidos: nas emendas entre filmagens, imagens e os sons. Assim,

\footnotetext{
3 Muitas das atividades utilizadas em nosso mapeamento do encontro efetivado entre cinema e educação infantil são desdobramentos dos princípios e estratégias presentes em pesquisas colaborativas entre professores universitários e docentes da Educação Básica, conforme as entende Desgagné (2007), especialmente a consideração de todos os pontos de vista na co-construção de conhecimentos que, por sua vez, devem estar "ligados a uma dada prática profissional [...] no contexto real em que ela é atualizada", considerando também os "limites e recursos existentes em situações reais, observando em que contribuem para a sua estruturação. Ademais, isso significa que tal construção não se faz sem considerar a compreensão que o docente tem das situações práticas, no interior das quais ele se desenvolve" (DESGAGNÉ, 2007, p. 9).
} 
poderíamos falar de uma pedagogia que parte de um princípio de igualdade, em que o lugar do mestre não garante a emancipação ou 0 aprendizado do outro. O espectador [os professorescineastas] não pode esperar do mestre [o processo de montagem] respostas prontas para o que fazer ou como fazer (MIGLIORIN; BARROSO, 2019, p. 104).

Segundo Edgar-Hunt, Marland e Rawle (2013), "a montagem (do francês, montage) é um termo geral para edição no cinema" e que "agora é mais frequentemente usada para descrever um modo particular de edição intelectual ou não realista, que cria significado a partir de um material não relacionado" (EDGAR-HUNT; MARLAND; RAWLE, 2013, p. 162). Além disso, os termos montagem e edição são territórios conceituais contestados tanto na linguagem dos professores ${ }^{4}$ quanto na dos cineastas $\mathrm{e}$ pesquisadores do cinema (MIGLIORIN; PIPANO, 2019). Ao encontro disso, optamos por fazer uma ligeira distinção entre eles a partir de nosso próprio contexto cinematográfico escolar.

Chamamos de montagem os gestos eminentemente artísticos e realizados 'na cabeça e na tela', e de edição, os gestos mais técnicos realizados 'no mouse, no teclado e na tela'. Com isso, temos deixado a palavra edição reservada ao conjunto de gestos do processo de montagem que se realiza através de recursos digitais presentes nos chamados programas de edição audiovisual.

Fizemos isso por dois motivos: um deles é o uso comum do verbo editar, entre professoras e professores, para designar os saberes relativos aos programas de edição digital utilizados para controlar (e transformar) os sentidos das imagens e sons de um filme. O outro é que em muitas de nossas experimentações com o cinema fizemos filmes a partir de 'simples montagens', ou seja, somente juntávamos duas ou mais pequenas filmagens, exercitando essa inteligência típica do cinema que é juntar filmagens para produzir outros sentidos. Por isso as aspas na expressão 'simples montagens', pois não há nada de simples nisso. Buscar fazer emergir sentidos outros nas imagens a partir da 'simples' colocação de uma após a outra é um aprendizado central no cinema e articulador de sua pedagogia, a qual subjaz aos processos de montagem (e edição) relatados neste artigo.

Entendemos, portanto, que no Cineclube Regente/Cha têm ocorrido dois processos de experimentação e aprendizagem que, apesar de simultâneos, fazem-se de maneira a-paralela (DELEUZE; GUATTARI, 1997) e seguem caminhos distintos: o de montar e o de editar. O primeiro, mais amplo, percorre mais diretamente o universo da

\footnotetext{
${ }^{4}$ Edição e montagem são duas palavras usadas quase como sinônimas para a grande maioria das professoras e professores que conhecemos, mesmo para aquelas/es que fazem filmes.
}

Revista Digital do LAV - Santa Maria - vol. 14, n. 1, p. 197 - 219 - jan./abr. 2021 ISSN 1983 - 7348 
arte (e) do cinema, com suas infinitas possibilidades de criação de sentidos, e o último, mais restrito, percorre o universo das tecnologias e possibilidades dos programas de edição digital para dar sentido "nas telas" ao que se montou "na cabeça". Dessa forma, podemos dizer que, em nossas experiências com o cinema na educação infantil, a montagem, via de regra, antecede a edição. No entanto, sabemos que a separação entre ambas, no processo de criação de um filme, é praticamente impossível ${ }^{5}$.

Desde o início, tivemos uma quantidade enorme de filmagens realizadas pelos integrantes do Cineclube. Havia mais filmagens do que conseguíamos montar e editar. Assistíamos o que era possível na tentativa de selecionar o que poderia 'vir a ser filme' uma tarefa difícil, porque estávamos na busca de entender o que era esse 'cinema' que estávamos inventando na escola de educação infantil. Afinal, nós fazemos filmes para e com crianças e bebês, isto é, são imagens que necessitam de certo cuidado.

Participamos de diversos cursos sobre cinema no Museu da Imagem e do SomMIS - Campinas, no Centro de Formação, Tecnologia e Pesquisa Educacional Prof. Milton de Almeida Santos - CEFORTEPE/SME - Campinas e na Faculdade de Educação da Universidade Estadual de Campinas/UNICAMP em busca de pistas para nossa atuação com o cinema na escola de educação infantil. Foram cursos bastante abrangentes, pois estudamos sobre uso de câmeras/celulares, enquadramento, posições de câmera, diferentes planos cinematográficos, e como treinar o olhar, ou seja, sentir o que pode ser considerado importante ou banal, mas, sobretudo, o que pode ser considerado cinematográfico.

Paralelamente a esses cursos, realizávamos muitas experimentações com cinema nas escolas: colocar música e tirar música; filmar tudo ou quase nada; usar imagens dos arquivos, ou da câmera em movimento, parada, escondida e/ou em veículos; utilizar filmagens feitas por professores, por crianças e bebês; entrevistar adultos e crianças; usar som e imagem simultâneos e/ou som e imagem editados desconectados; filmes de um único plano sequência, filmes com poucas ou com muitas cenas; filmes roteirizados ou não; filmes produzidos para os pais e responsáveis, para mostras de cinema ou para nada.

Realizamos filmagens e filmes que foram emergindo ali, naquele lugar-escola, na medida em que o cinema se tornava um 'problema' para nós. Importante dizer que algo se torna 'problema' quando escapa da rotina e exige que pensemos, entendendo que "[o]

\footnotetext{
5 Tendo em vista a complexidade do que tivemos que simplificar, gostaríamos que leitores e leitoras se lembrassem de ler essas distinções entre montagem e edição tendo no pensamento que, mesmo para nós, 'não é bem assim'. Há sempre algum momento, algum filme que coloca essas distinções em suspenso.
} 
ato de pensar não decorre de uma simples possibilidade natural; ele é, ao contrário, a única criação verdadeira. A criação é a gênese do ato de pensar no próprio pensamento" (DELEUZE, 1987, p. 96). Nesse sentido, um 'problema' é parte do processo de criação, porque exige um passo a mais, um aprendizado, ou seja, exige reflexão para criar modos novos de agir, até mesmo inusitados, para vivenciarmos o que nos problematiza no mundo ao nosso redor. Em nosso caso, o 'problema' era o cinema e, inevitavelmente, a escola que ele fazia emergir em suas imagens e sons.

\section{Burburinho: tempo e espaço específicos}

O tempo necessário para realizar a edição de um filme é algo complicado, pois pressupõe planejamento, seleção e revisão, o que demanda bastante tempo. Em um ambiente no qual estamos realizando alguma atividade, há sempre um burburinho e o ritmo é mais dinâmico, como o de uma escola de educação infantil. Fazer algo que demanda outro ritmo pode, muitas vezes, parecer estranho aos que olham de fora, pois o tipo de atenção detida que a edição exige pode parecer ausência de atividade.

Às vezes, editar pode ser algo estressante, dependendo do que temos e o que pretendemos com aquelas filmagens. Editar não é recortar e colar, mas pensar o que se pretende fazer e tomar decisões, ou seja, é realizar muitas escolhas. Na dúvida, experimenta-se mudar a sequência da montagem, o que estava no fim vem para o meio ou para o início do filme e vice-versa; experimenta-se diferentes estilos de música; acrescenta-se sons, ruídos que não estavam nas cenas originais.

No processo de edição quase tudo é permitido, visto que, devido a questões éticas, nem tudo pode ir para a tela. É no processo de montagem/edição que, muitas vezes, notamos determinados acontecimentos, falas 'indevidas' ou algo que se passa além da cena principal, no campo ou no extracampo e que necessitaria ser retirado por motivos éticos. Tudo isso necessita atenção, pois algumas cenas precisam ser subtraídas para evitar constrangimentos de crianças e profissionais.

Outro exemplo seria a própria fragilidade das imagens resultantes da filmagem. Acontece de uma cena estar ótima, mas algo mais se passa ali e temos que alterar a cena, cortar um trecho, substituir o som. Já houve caso de um profissional da escola enviar uma filmagem muito interessante realizada por uma criança: a forma como ela interagia com a câmera e o jeito de fazer as filmagens eram muito simpáticos, porém o extracampo sonoro não ajudava, pois em alguns momentos chamava mais atenção do 
que a cena principal. Na escola, conversas entre adultos, adultos e crianças, crianças com crianças etc., além de ruídos, barulhos, sons, falas, choros, são comuns e são captados pelo celular, sendo necessário estarmos atentos a isso. Esse extracampo até poderia vir a ser parte do filme desde que o foco fosse o que se passava nele.

Muitas vezes, o que mais 'prejudica' a filmagem na escola são as vozes que chegam do extracampo, complicando o processo de montagem/edição, uma vez que, em determinadas ocasiões, a fala de uma criança é entrecortada pela fala do adulto que faz diversas interferências, participa da conversa e monopoliza o diálogo. No processo de edição não conseguimos separar a fala de cada um, porque o áudio é único, captado pelo celular.

No entanto, outras vezes, esse mesmo adulto consegue perceber que sua participação é necessária para o cinema por diversos motivos. Por exemplo, quando uma criança está com a câmera ela faz perguntas, cumprimenta, quer interagir com quem está sendo filmado, dizendo "oi, olha eu estou filmando"6. A interação das crianças com os adultos é muito comum, e necessária, mas a experiência do cinema na escola aponta que seria interessante chegar ao 'tom' certo dessa participação no diálogo com a(s) criança(s) que filma(m). Isso parece já estar ocorrendo, uma vez que alguns profissionais estão mais cuidadosos e, ao ver que estamos filmando, diminuem o tom da voz e interagem com a criança somente quando necessário.

Uma escola é sempre um lugar de burburinho, de muita interação entre as pessoas e são frequentes as conversas paralelas, as vozes que são captadas no extracampo. Para lidar com essas situações, uma das integrantes do Cineclube, que realiza filmagens com as crianças na sua sala, adotou a estratégia de afixar na parede um pequeno cartaz com os dizeres: estou gravando. Isso permitiu que as pessoas, ao chegarem e perceberem a filmagem em andamento, parem e esperem até a gravação terminar, evitando algum atropelo ou 'ruído' na filmagem.

\section{Intuição e aprendizagens: o banal e o mundo}

Depois de três anos de Cineclube Regente/Cha, pensamos que nosso trabalho de montagem e edição teve seu percurso inicial baseado em muita experimentação e uma boa dose de intuição. Tanto na montagem quanto na edição nos parece que seguíamos

\footnotetext{
6 Se a câmera está em modo selfie, as crianças falam e interagem consigo mesmas, fazendo brincadeiras, gracejos, ou se observam, interessadas em suas próprias imagens.
}

Revista Digital do LAV - Santa Maria - vol. 14, n. 1, p. 197 - 219 - jan./abr. 2021 ISSN 1983 - 7348 
muito a intuição, confirmando o que escreveu o cineasta experimental Jonas Mekas em 1967:

\begin{abstract}
A montagem se tornou um processo intuitivo. [...] $\mathrm{O}$ cineasta de vanguarda hoje faz sua "montagem" da mesma maneira que o poeta e o pintor o fazem: intuitivamente, automaticamente, durante o processo de filmagem (criando). [...] você desenvolveu seu senso estético: vendo outros filmes e frequentando outras artes. Não se pode fazer tudo isso em duas semanas, logo antes da filmagem, bang, desse jeito. Isso deve ser feito durante toda sua vida e constantemente (MEKAS; MOURÃO, 2013, p. 110-111 destaques do original).
\end{abstract}

De muitas formas o cinema que fazemos na escola de educação infantil é tributário das vanguardas dos anos 1960 e 1970 e de suas criações intuitivas. Especialmente ao montar, notávamos que íamos buscar um caminho, um mote para dar um sentido específico ao que estávamos montando/editando através da intuição. Experimentar foi a saída na busca por um produto que representasse algo significativo para as crianças - tentávamos entender o que seria importante para elas, suas reações, e o que realmente Ihes seria atraente.

Intuição é uma palavra muito importante, pois pensamos que, mesmo com todos os cursos que fizemos, tem sido ela que nos guia nas experimentações nesse novo universo em que o cinema adentrou, o das escolas de educação infantil. É a ela, por exemplo, que recorremos quando temos muitas imagens para montar ou editar sem roteiro predefinido. Ela não se vê, não se pega, a intuição está dentro de nós, mas é acionada pelas coisas que nos chegam do mundo. Foi a intuição - aliada aos conhecimentos sobre filmagem e aos conhecimentos educativos que nos legaram um olhar atento para as crianças - que levou um dos autores deste texto a fazer o filme Sohlepse (GUARI, 2018)7.

Em nosso trabalho cotidiano com os bebês, notamos que, quando o celular era colocado no modo selfie, aquelas pequenas crianças viam a tela como um espelho, pois 'se' viam ali, como que 'espelhados'. A montagem de Sohlepse foi toda pensada a partir disso, para dar a ideia ao espectador de que as crianças-personagens estariam se vendo num espelho ${ }^{8}$, por isso o título do filme é a palavra espelhos ao contrário.

\footnotetext{
${ }^{7}$ Disponível em: <https://www.youtube.com/watch?v=GLgXcgmZT6g>.

${ }^{8}$ No relato sobre a produção desse filme, seu realizador, Mauro Guari, escreveu: "A relação bebê/tela-câmera mudou e muito. Ao se verem refletidos, começaram a tratar a câmera de uma forma diferente. Não era apenas um objeto. Era um objeto que mostrava o rosto deles próprios ou outros rostos semelhantes aos deles. Na verdade, não tenho de forma clara se os bebês nessa faixa etária já se reconhecem como eles mesmos. Mas o fato é que começaram a tratar a câmera de outra forma, um pouco mais 'carinhosa'" (OLIVEIRA JR; AMARAL, 2019 , p. 113 - destaques do original).
} 
Com o passar do tempo, outras coisas foram sendo incorporadas ao processo de montagem e edição, aprendidas com os acertos, erros e novas ações do Cineclube Regente/Cha. Por exemplo, quando os filmes produzidos na escola passaram a ser exibidos às famílias, passamos a ter a preocupação de selecionar imagens e produzir filmes que fossem interessantes também para os familiares. Assim, as crianças não eram mais o único foco e interesse de nossas sessões de cinema.

Posteriormente, quando decidimos enviar nossos filmes para Mostras de cinema, a escolha de imagens (que é parte daquilo que estamos chamando de montagem) e a edição passaram a sofrer influência do tema ou estilo exigido em determinada Mostra de cinema para a qual pretendíamos enviar um filme. Essas mudanças serão mostradas mais adiante, nos relatos dos processos de montagem e edição.

Antes, porém, cabe dizer que o trabalho de montagem e edição, apesar de bastante intuitivo, foi atravessado por diferentes processos de aprendizagem, artísticos e técnicos, os quais se deram tanto em nossos esforços individuais quanto nas reuniões do Cineclube e do Projeto Lugar-escola e cinema, que aconteciam semanalmente e nos ajudavam a refletir sobre o que produzíamos.

Ao finalizarmos a edição de um filme e o assistirmos juntos nas nossas reuniões, passávamos a observar o que mais poderia ter sido aproveitado. Apesar de, muitas vezes, não alterar o filme assistido e levar a uma nova montagem/edição, isso reverberava em outro momento e nos ajudava a pensar nas possibilidades de trazer outros elementos do cinema quando filmávamos. Uma coisa alimentava a outra: realizar a montagem/edição de filmes levava a ajustar nossas escolhas ao produzir imagens, fazendo com que a montagem de alguns filmes se iniciasse ainda no momento das filmagens.

Essas questões conceituais nos levaram a refletir mais sobre as filmagens que produzíamos - como elas eram realizadas (câmera parada, ângulo, enquadramento, perto, longe...) - e sobre a seleção das filmagens para compor um filme ${ }^{9}$. Ao montar/editar, passamos a prestar mais atenção e a pensar mais sobre o que filmar e como filmar. Além disso, ficamos mais atentos às filmagens já realizadas, uma vez que, quando estamos fazendo a seleção das filmagens para compor um filme, muitas vezes acontece de estarmos assistindo a uma cena interessante, pensando em uma possível montagem e, de repente, ela é descontinuada: um detalhe, uma cena que acontecia fora do foco principal é notada pela primeira vez e muda o sentido daquela filmagem. $O$

\footnotetext{
${ }^{9}$ Grosso modo, temos dito que filme é uma obra pronta e filmagem é todo material filmado que 'ainda não é filme', mas que conserva a potência de vir a ser.
} 
mundo visto continua mudando mesmo após ser filmado, pois 'ver o mundo' implica sempre na possibilidade de ver algo que ainda não havia sido visto, notado, significado.

No ensaio Homo Spectator (MONDZAIN, 2015, p. 15), a autora nos fala um pouco sobre isso, sobre o espanto do chamado 'homem primitivo' ao 'ver o mundo'. O mundo aqui seria o grande espetáculo das coisas vistas pela primeira vez ou revistas de uma forma diferente. O mundo muda a todo instante. Ver as filmagens feitas nas duas escolas fez com que a nossa visão se alterasse ao vermos esse mundo filmado e projetado diante de nós. Em muitos momentos, foram os filmes que fizeram com que notássemos alguma coisa que já estava à nossa volta.

É incrível como as coisas mudam após serem filmadas. Certa vez, quando filmávamos no borboletário da escola, uma das moças da cozinha passou e perguntou: "Me deixa ver?". As imagens eram de algumas flores, borboletas e abelhas; coisas que estavam ali o tempo todo. No entanto, a exclamação que fez ao vê-las foi como se antes Ihe fossem invisíveis: "Nossa! Que diferente! Nunca tinha reparado". Temos aí um exemplo de como algo corriqueiro transforma-se em imagem, no sentido de Mondzain, aquilo que surpreende uma pessoa e a faz ver, entrar em contato com o visível do mundo. Em outras palavras, faz com que essa pessoa se sinta uma espectadora. Tornar as pessoas espectadoras é uma das magias do cinema. O diretor de cinema Cao Guimarães diz que "tudo é filmável, é cinematográfico. Depende como você vê as coisas"10.

Nos termos de Mondzain (2015), o mundo fez-se imagem, ou seja, estabeleceu-se como visível para ela, assim como se fez visível para nós, uma vez que "pode-se ainda dar o nome imagem a tudo que faz de um sujeito que vê um sujeito capaz de estabelecer com o visível uma relação de espectador" (MONDZAIN, 2015, p. 18). Essa relação entre 'visível' e 'espectador' é mutante. Não podemos dizer que o que vemos é a mesma coisa que o outro vê. Ademais, as relações entre eu (espectador) e a coisa vista - o outro podem mudar com o tempo e quando editamos uma imagem. A montagem/edição nos parece fundamental no cinema para que ele nos torne espectadores e, com isso, possa tornar o mundo imagem, no sentido dado a essa palavra por Mondzain (2015).

O cinema que temos produzido na escola tem feito com que vejamos as coisas de outras maneiras e, com isso, tem mudado nossa percepção na hora de filmar, montar e editar, alterando nossas escolhas do que vai ser usado, do que vai ser descartado, das coisas que consideramos banais ou não. Aliás, o que antes era banal e, por isso,

10 Entrevista Ver é uma fábula. Disponível em: <https://www.youtube.com/watch?v=n88Ieqcy1Rw>. Acesso em: jan. 2019.

Revista Digital do LAV - Santa Maria - vol. 14, n. 1, p. 197 - 219 - jan./abr. 2021 ISSN 1983 - 7348 
descartável tem se tornado matéria-prima do cinema sem perder sua condição de banalidade. E isso nos parece um efeito, sobretudo, dos processos de montagem e edição, os quais exigem de nós longos e reiterados gestos de atenção (KASTRUP, 2009) às filmagens feitas nas escolas.

Fazer filme na escola tem seus desafios, suas nuances, que demandam fazer escolhas e a atenção é algo que vamos aprendendo a desenvolver. Não uma atenção de somente estar atento ao fato, mas aos detalhes, às minúcias do que acontece, ao que se passa com as crianças, com o espaço, com as pessoas. Mais ainda, e principalmente, uma atenção às próprias filmagens realizadas ali. Notamos que, ao repararmos com mais atenção nas filmagens, o banal do cotidiano emerge como potência de cinema. Isso ocorre porque, quando estamos montando e principalmente editando, nossa atenção está toda ali, em tudo que acontece nas filmagens, ruídos, sons, cores, luzes e sombras, pessoas; o que se passa no plano geral, no extracampo, no detalhe de cada cena.

Montar (e editar), portanto, altera nosso olhar, faz vermos as coisas de outras maneiras e nos leva a considerar o que filmar e como filmar. Passamos a ter maior atenção sobre todo o processo do cinema, modificando os processos de filmagem, seleção e edição. A aprendizagem do e com o cinema acontece nesse processo de fazer, refazer, experimentar, inventar modos de fazer cinema, o que, em nosso caso, está diretamente relacionado a estabelecer relações com espectadores: crianças, familiares, Mostras.

Fazer cinema na escola aguçou nossos sentidos. Passamos a olhar mais intensamente para esse lugar-escola, ampliando e alargando as relações humanas e a relação com o espaço, despertando sentidos adormecidos pelos fazeres rotineiros, levando-nos a reparar em detalhes que eram quase imperceptíveis, revisitando e apreciando-os por outro ângulo, em outras distâncias, em outras composições. Esse olhar mais atento se alarga para as crianças e seus fazeres, seus gestos, movimentos, falas, expressões de espectadores diante da cena de um filme. Tudo passa a ganhar outra forma, outro corpo.

Dessa maneira, os sentidos são aflorados. Elementos pouco admiráveis e quase imperceptíveis na escola ganham intensidade de sentido, revelando o vento que agita as pequenas folhas no chão, o perfume das flores, a brisa, a joaninha imóvel agarrada à folha que trepida ao vento, a formiga que carrega algo, as galinhas que passeiam pela escola, as refeições das crianças, os sons, ruídos... é o cinema potencializando percepções e sensibilidades. 


\section{Editando entre afetos, roteiros e espectadores}

Cada edição é singular. Saber a técnica não é tudo, ou seja, cortar, colar, dominar o programa de edição não é suficiente para montar e finalizar um filme. No caso das experimentações com cinema do Cineclube Regente/Cha, normalmente vemos as filmagens que fizemos e ficamos atentos a 'algo' que nos indique a possibilidade de fazer um filme em que aquele 'algo' apareça. Esse 'algo', inicialmente indefinido, pode ser quase tudo ou mesmo tudo o que aparece numa filmagem/imagem. Portanto, na maior parte das vezes, é justamente 'algo' presente nas filmagens que de repente nos afeta e nos faz saber o que se pretende com aquelas imagens, que tipo de filme poderia ser realizado com elas.

Podemos dizer que a edição começa naquilo que denominamos montagem, ao fazermos as escolhas das cenas que vão para o filme. Pode acontecer de, no processo de edição, recorrermos a algumas cenas que inicialmente haviam sido deixadas de fora, porque ao montarmos efetivamente (colocarmos na 'linha do tempo' da tela, ou seja, editarmos), notamos que 'faltou algo'. Voltamos àquelas cenas na busca de 'outro algo' que ajude a dar mais sentido a uma determinada sequência. Ocorre também de filmarmos outras cenas para compormos o filme.

Outra possibilidade é trazer outros elementos para o filme, como desenhos das crianças ou falas que são gravadas depois. Fizemos isso em filmes como Cigarras (GUARI, 2019) ${ }^{11}$ e O de Ó eu Mauro (GUARI; AMARAL, 2018) ${ }^{12}$. No processo de edição, podemos recorrer a outros artifícios, experimentar com 0 som, com as imagens/desenhos, há várias possibilidades e elas, muitas vezes, são 'solicitadas' pelo próprio processo de montagem quando atravessado pela edição.

No entanto, existem filmagens que já são quase o filme pronto. Não há muito que montar ou editar, mas isso só é notado quando as assistimos por completo. Então, muitas vezes, surpreendemo-nos, porque, em meio às filmagens, aparecem cenas perfeitas para montar um filme. O filme 'quase' pronto é, portanto, resultado de uma observação atenta diante de tantas filmagens realizadas na escola por nós e pelas crianças. Ele, o quase filme, está ali esperando que o encontremos. Esse encontro se faz mediado, em grande medida, pelo espectador imaginado para o filme, aquele que buscamos afetar através da montagem. Contudo a experiência no Cineclube tem nos mostrado que nossas produções cinematográficas são frutos da seleção de um amontoado de filmagens realizadas na escola. Ou seja, juntamos fragmentos de algumas

${ }^{11}$ Disponível em: <https://www.youtube.com/watch?v=0aYosxOhL6g>.

12 Disponível em: <https://www.youtube.com/watch?v=4w0BEM98Vt4>. 
delas na tentativa de chegarmos ao que queremos, sendo que aquilo que almejamos muitas vezes emerge de algum desses fragmentos.

Normalmente aquilo que aparece nas filmagens como algo novo, inusitado, que foge da rotina é o que faz com que produzamos filmes, com que façamos cinema. Por isso, podemos dizer que nossas escolhas dos fragmentos que usamos para fazer um filme estão em oposição ao que descartamos por entendermos ser banal, ainda que saibamos que o material não utilizado naquele momento poderá vir a ser usado em outro. Ou seja, se no primeiro momento, a condição de banalidade encontra-se na própria cena filmada, no segundo essa mesma banalidade pode vir a compor um filme cuja força emerge da relação com outros fragmentos ${ }^{13}$. Nesse sentido, podemos dizer também que muitos filmes produzidos na escola não são roteirizados, pois não seguimos um script, nem normas. No entanto, há exceções.

No filme Gustavo entrevista (AMARAL, 2019) ${ }^{14}$, por exemplo, a sequência em que as cenas foram gravadas já indicava o filme, pois a realizadora teria que pensar a ordem na qual gostaria que os protagonistas aparecessem e com que cena o iniciaria. Na montagem desse filme, tivemos que pesquisar a parte técnica da edição, porque a realizadora queria justapor os quadros ${ }^{15}$. Havia duas filmagens de duas crianças conversando; em uma delas uma das crianças está com o celular filmando; na outra, um adulto filma toda a ação. Tínhamos duas filmagens e o desejo de mostrar os dois pontos de vista, o da criança e o do adulto, portanto, um 'problema' de cinema. Para isso, resolvemos justapor as imagens, mas sem colocar os quadros lado a lado. Primeiro tivemos que buscar como fazer isso tecnicamente e foi assistindo a vídeos tutoriais no youtube que aprendemos a colocar dois quadros simultâneos na tela.

Nesse processo de montagem/edição realizamos alguns experimentos. Primeiro, tentamos colocar as imagens em sequência uma da outra, mas de início já descartamos essa possibilidade, porque não passava a mensagem de como as filmagens haviam acontecido, simultaneamente. Ao dividir a tela mostrando as duas imagens, e sincronizando-as, podíamos ver as duas filmagens ao mesmo tempo, sendo possível visualizar o que cada um havia filmado. O tempo que o quadro pequeno ficaria sobreposto à tela maior também foi algo muito pensado.

\footnotetext{
${ }^{13}$ Cao Guimarães fala sobre isso na entrevista Ver é uma fábula. Para esse cineasta nada é banal. Tudo que vemos e sentimos é passível de ser filmado e virar filme. E tudo que já foi filmado, se num primeiro momento deixamos de lado, pode, no futuro, virar um filme. No Cineclube Regente/Cha já fizemos isso no filme Caiu o xilofone? (GUARI, 2020), disponível em: <https://www.youtube.com/watch?v=AzY1Oh7zV14\&t=181s>.

${ }^{14}$ Disponível em: <https://www.youtube.com/watch?v=HgwLHKh9-II>.

15 Nessa frase fica clara a distinção que buscamos fazer entre montagem e edição, estando a primeira mais relacionada ao domínio estético (a relação entre os quadros e as filmagens simultâneas) e a segunda mais relacionada ao domínio técnico, bem como os distintos aprendizados que engendram.
} 
Não sabendo decidir qual cena ficaria no quadro menor da tela, fizemos duas versões, alternando cenas e analisando a composição que ficaria melhor. Assistindo ao filme finalizado no telão da escola, consideramos que ficaria melhor se tivéssemos deixado a tela com os dois quadros simultâneos por um tempo menor. No entanto, o filme já havia sido enviado para a Mostra Kino Campinas, fazendo com que o considerássemos finalizado.

Ocorreu com esse filme o que ocorre na maioria das vezes: ao assistir os filmes prontos começamos a pensar o que modificaríamos neles. De alguma forma, isso se refere ao momento em que nos deslocamos da condição de realizadores dos filmes para a condição de espectadores, para a condição de aprendizes de cinema, quando a montagem atua como mestre, um mestre que ignora nossos objetivos e saberes, fazendo com que selecionemos os aprendizados que cada filme nos traz a partir de nosso próprio encontro com as imagens e sons diante da tela de cinema.

No cinema comercial, são os espectadores que, em grande medida, modulam as escolhas dos realizadores, uma vez que seus filmes visam grandes públicos e muito dinheiro. No entanto, nas produções cinematográficas não comerciais os espectadores muitas vezes um público específico ou especializado - também atuam como moduladores das escolhas estéticas e éticas, e suas reações a uma obra fílmica certamente se dobram nas escolhas futuras dos realizadores.

Na escola isso não é diferente. As reações de crianças e adultos que presenciam as sessões do Cineclube Regente/Cha são bastante consideradas em nossas conversas sobre o cinema que estamos inventando, sendo um dos principais moduladores éticos e estéticos das edições de filmes posteriores, bem como das escolhas curatoriais para as próximas sessões do Cineclube.

A importância dos espectadores se dá porque os sentidos que as pessoas vão dando ao filme ou a alguma cena dele fogem ao controle daquilo que o realizador pretendia. Esse 'escape' de sentidos e propósitos de um filme nos ajuda a entender o que filmamos e editamos. É a partir dos olhos desse outro - espectador - que nosso cinema se faz, inventa-se, entende-se ou não, reinventa-se. Como o diretor de cinema Cao Guimarães diz em seu ensaio Cinema de Cozinha,

não podemos desconsiderar que fazemos filmes para que alguém os veja, e mais que isso, para que alguém reinvente o tempero através da saliva, reinvente a imagem através do líquido ocular, do prisma ocular, das veias oculares que transportam toda a informação para ser processada em um cérebro único, 
personificado, individual, reinventando o filme, multiplicando-o (GUIMARÃES, 2008, s/p).

Entendemos que o principal objetivo de pensar, filmar, montar e editar um filme é exatamente para que ele seja visto. E quem vai ver nossos filmes? O outro, aquele que não sou eu, o outro que o próprio cinema inventa, como espectador. Aquele que vai apreciar, entender, gostar, emocionar-se, aplaudir ou não a nossa obra, nossa cria composta com aquelas imagens que não descartamos, que não consideramos banais cinematograficamente.

No Cineclube temos alguns tipos de outro:

- As crianças;

- As famílias/comunidades;

- Os profissionais da escola;

- Os integrantes do Cineclube Regente/Cha;

- As Mostras de cinema que participamos;

- Nós mesmos, os cineastas que realizamos o filme.

Quanto às crianças, famílias e profissionais, parece que temos uma boa receptividade. Nosso maior 'problema' tem sido com as Mostras, uma vez que temos de nos adequar a elas. As Mostras nos chegam como um 'outro' - espectador - não inventado por nós e que, justamente por isso, atua na inventividade de nosso cinema. Por exemplo, o filme FiOs TrAmAdOs Ao AcAsO (AMARAL; LEMOS; OLIVEIRA JR, 2019) ${ }^{16}$ foi feito para o tema Mulheres: terras e movimentos, da $14^{\circ}$ Mostra de Cinema de Ouro Preto-CineOP.

\section{Montagem coletiva e edição individual: FiOs TrAmAdOs Ao AcAsO}

No primeiro semestre de 2019, realizamos a produção coletiva do filme FiOs TrAmAdOs Ao AcAsO. Decidimos experimentar não filmar nada, mas utilizar imagens existentes em nossos arquivos do Cineclube Regente/Cha. Para realizá-lo, selecionamos filmagens que havíamos feito no ano anterior. Fizemos o filme com material que talvez nem usássemos mais, bem como fizemos a seleção dele de maneira coletiva. A seguir, esmiuçamos o processo de montagem e edição do filme.

${ }^{16}$ Disponível em: <https://www.youtube.com/watch?v=_0KEVQ8MSF4\&t=1s>. 
A partir de nossas memórias, escolhemos filmagens que haviam sido feitas por duas crianças de menos de 2 anos. Na época, foi-lhes oferecido o celular para que 'registrassem' suas andanças pelo parque da escola. Das várias filmagens que fizeram, foram selecionados dois planos-sequência que, somados, davam mais ou menos 40 minutos.

Decidimos realizar entrevistas com as mulheres que trabalham nas duas escolas para compor com as imagens filmadas pelas crianças. Foram entrevistadas 12 mulheres, entre cozinheiras, serventes, professoras e agentes da educação infantil das duas unidades escolares. Foram cerca de 35 minutos de conversas gravadas somente em áudio a partir de algumas perguntas e palavras ditas por quem entrevistava. Perguntas e palavras que pudessem suscitar memórias, a exemplo de: "O que é TPM para você?; Conte algo interessante ou engraçado que aconteceu na escola; Fale sobre ser uma trabalhadora nessa escola; A palavra cansaço te remete a alguma coisa?"

Uma das entrevistadas cantou duas músicas, sendo uma delas a música Mulher, do Erasmo Carlos, mas foi a outra que veio a ser escolhida para finalizar o filme: uma música originada de um desenho animado que teve sua letra alterada pela entrevistada que a canta da mesma maneira que cantava para seus filhos quando eram pequenos. Portanto, uma música que foi gravada pela primeira vez. Tínhamos, então, a matériaprima bruta audiovisual para fazer o filme: as imagens dos planos-sequência e as falas das entrevistadas.

Para pensar a montagem, assistimos juntos às filmagens selecionadas em uma reunião do Cineclube. Todos contribuíram sugerindo quais partes dos dois planossequência eram as mais interessantes, onde cortá-las, a ordem para a sequência das cenas e um nome inicial para o filme, que depois foi sendo repensado no grupo do whatsapp Cineclube Regente/Cha ${ }^{17}$ até chegarmos a um acordo: FiOs TrAmAdOs Ao AcAsO.

17 O grupo Cineclube Regente/Cha tem nos ajudado muito na comunicação entre os membros do cineclube, em especial nos processos que implicam em decisões coletivas. 


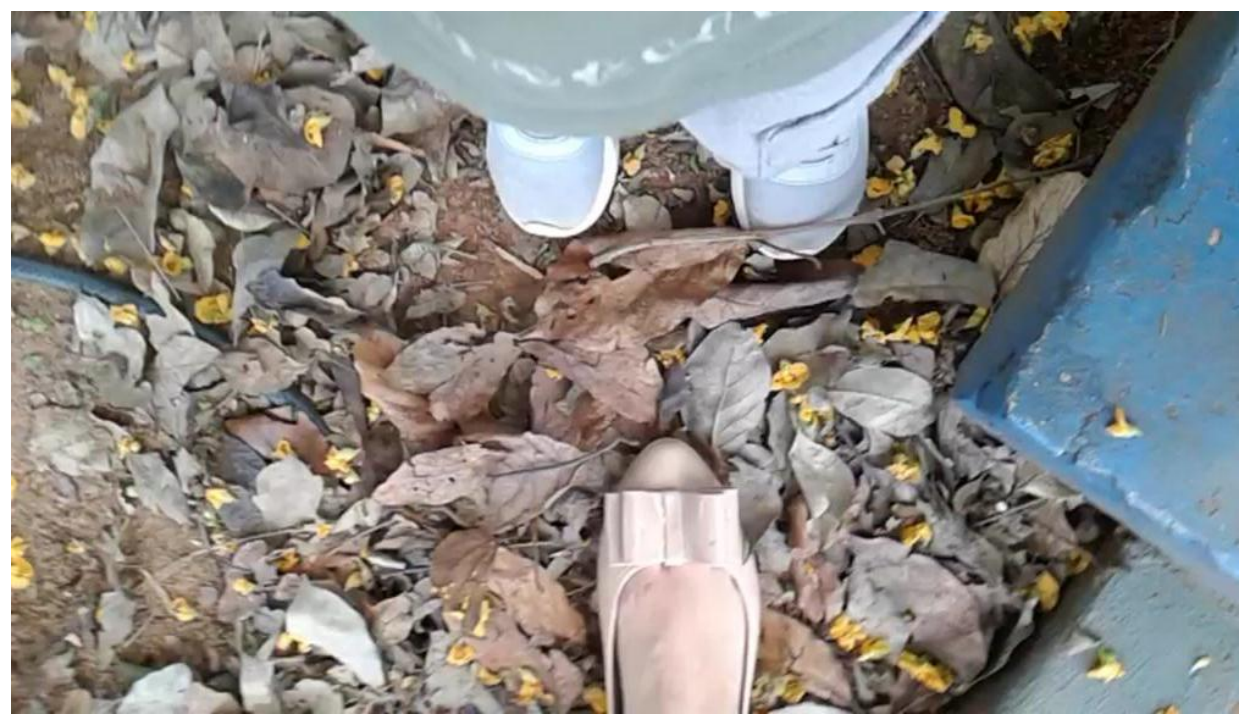

Figura 3: Último fotograma do filme FiOs TrAmAdOs Ao AcAsO Fonte: Arquivo Cineblube Regente/Cha

Dos dois planos-sequência foram gerados quatro fragmentos que, juntos, tinham cerca de 10 minutos, duração máxima permitida pela Mostra. A imagem acima (Figura 3) é o frame inicial de um dos planos-sequência, mas por considerarmos que representava perfeitamente o sentido geral que gostaríamos de dar ao filme optamos por finalizá-lo com ela. Dessa forma, o plano-sequência em que ela aparece foi invertido, tornando sua imagem inicial a imagem final do filme. Ao ouvir o áudio ininteligível que resultou dessa inversão digital, decidimos que o manteríamos assim, explorando a sensação que muitas vezes temos na escola, onde o burburinho sonoro ininteligível é quase constante.

Definidas as imagens que seriam vistas ao longo do filme, partimos para a escolha dos sons que as iriam acompanhar. Primeiramente definimos os momentos em que o som ambiente das filmagens seria mantido, principalmente os momentos em que as crianças balbuciavam palavras e aqueles nos quais os ruídos do parque deixavam claro o contexto onde as filmagens foram feitas.

Os depoimentos colhidos das profissionais da escola por vários integrantes do Cineclube foram enviados para nosso grupo de WhatsApp. Eles já não estavam em sua íntegra, mas somente algumas partes pré-selecionadas, uma vez que havíamos definido coletivamente que seria feita uma primeira seleção de trechos pela(o) entrevistador(a), apontando quais momentos da entrevista consideravam mais interessantes para comporem o filme. Ao ouvi-los foi definido não alocar entrevistas que tivessem o mesmo 'tom/discurso', próximas umas das outras, promovendo mais estranhamentos que continuidades. 
No entanto, essa pré-seleção dos áudios não teve o efeito desejado, uma vez que a duração do conjunto deles ultrapassava o tempo de duração do filme. Sendo assim, coube ao editor fazer uma segunda seleção nesses trechos das entrevistas a partir da ideia geral de montagem que havíamos definido. Eles tiveram que ser ouvidos várias vezes e novamente recortados, porquanto tínhamos que analisar o tempo de cada um em relação ao momento do filme em que poderia ser alocado de maneira que não se sobrepusesse a outras falas ou aos momentos de som ambiente anteriormente definidos.

Foram diversos recortes na tentativa de encaixar os áudios das entrevistas, pois, se tirássemos certas partes, as falas ficavam sem sentido; se aumentássemos demais a duração de algumas delas, poderíamos ter que sobrepor uma sonoridade a outra. Essas decisões tomadas em grupo ajudaram para que a edição, individualmente realizada, fosse mais tranquila? Sim e não! Sim, porque com a pré-seleção dos áudios, a definição das cenas e a sequência delas - ou seja, a montagem - já definida, ameniza-se a responsabilidade do editor, que não precisa ditar o ritmo do filme, mas sim dar forma audiovisual aos desejos do grupo. Não, porque o editor teria, justamente, que tentar fazer o que foi pedido pelo grupo e nem sempre tudo fica como foi idealizado, uma vez que só no processo de edição pode-se realmente avaliar o que é possível utilizar naquele espaço disponível na 'linha do tempo' do programa de edição. Justamente por isso, a pré-seleção de falas teve que passar por diversas alterações na edição. Coube ao editor encaixar os recortes das falas das entrevistas dentro do que fosse possível, e se o editor tivesse limitações com relação ao programa de edição as coisas tenderiam a ficar mais trabalhosas.

A coletividade no processo de montagem fez com que o filme ganhasse força, e tivesse outra dinâmica ao expressar a visão de todos os envolvidos. Por exemplo, houve entrevistas que a princípio foram retiradas no processo de montagem, devido a uma ou a duas pessoas considerarem as falas desconexas com a narrativa do filme; mas como havia pessoas que não compartilhavam da mesma opinião, após ponderarmos um pouco, elas foram retomadas e fragmentos delas compuseram a versão final de FiOs TrAmAdOs Ao AcAsO.

Consideramos que especialmente esse processo coletivo aponta para a montagem como uma pedagogia do cinema, uma vez que ele exige que assistamos a cada versão finalizada, colocando-nos na condição de espectadores, e conversamos em torno dos múltiplos sentidos que emergem do filme. Podemos dizer então que essa pedagogia se dirige ao outro, aos espectadores (MIGLIORIN; BARROSO, 2019), mas também e, 
sobretudo, configura-se como uma pedagogia que se dobra sobre os realizadores, aprendizes de cinema.

No breve relato que fizemos, pode-se notar, por exemplo, o funcionamento da montagem sob os "princípios da heterogeneidade" ou uma "lógica dos múltiplos", uma vez que

a produção de sentidos e de conhecimentos [...] se faz por séries descontínuas e elípticas, por relações de choque entre elementos de diferentes naturezas no interior da materialidade do filme, por desfuncionalização do espaço e do tempo em uma ordem narrativa (MIGLIORIN; BARROSO, 2019, p. 99-100).

Aprendemos as potencialidades desse tipo de montagem experimentando-o em um filme com um tema específico, Mulheres: terras e movimentos, um tema que, a nosso ver, aparece 'em aberto' no filme, cujos sentidos foram deixados para os espectadores buscarem no encontro com as imagens e sons misturados ali, em suas emendas pouco nítidas.

\section{Inconclusões}

Em nosso trabalho no Cineclube Regente/Cha decidimos encontrar sentidos para as palavras montagem e edição, haja vista que para muita gente as duas palavras são sinônimas. Decidimos fazer essa distinção/diferenciação para que essas definições nos auxiliem como pensar os processos de aprendizagem e também como fazer o cinema que estamos produzindo. Optamos, então, pensar a edição de um filme como um ato técnico, usando os recursos de um programa de edição de imagens e montagem como processo mais ligado ao artístico.

Montar tem sido para nós, sobretudo, o ato de ver as imagens e procurar nelas alguns caminhos que possam levar a pensar e fazer um filme, sendo esses caminhos muito variados, conforme apontamos nos relatos que compõem este artigo. Neles podese perceber que se produzimos imagens com algum roteiro pré-determinado, buscamos nas filmagens realizadas aquelas que se adequem melhor a isso. Mas também se percebe que nunca fazemos um roteiro formal, aquele pensado e escrito que serve de guia para se fazer as filmagens, mas que algumas vezes há um roteiro que não é escrito e se configura como uma ideia de montagem que se tem 'na cabeça' e, a partir dela, procurase encontrar ou filmar as imagens adequadas. 
Montar um filme está ligado à criatividade, mediada pelo gesto de editar, colocar imagens em um editor digital, recortar e unir essas imagens para transformá-las em um filme. Dessa forma, montar sempre vem antes de editar, mas isso não impede que mudemos a montagem na hora da edição, quando o filme se faz visível em seu conjunto na 'linha do tempo' da tela. Além disso, nem tudo que montamos a nível mental é possível dar forma no editor de imagens, especialmente quando somos professoresaprendizes de cineastas. Então, se pensamos pedagogia como métodos, normas, estratégias usadas para ensinar alguma coisa para alguém, a pedagogia do cinema que fazemos, do nosso cinema de inventar, é uma pedagogia mais ligada aos nossos processos de aprendizagem, a nossa criatividade e a nossa vontade em fazer cinema, as nossas observações - como espectadores de nossas criações -, que muitas vezes podem virar filmes.

Da montagem intuitiva à montagem das multiplicidades, do direcionamento do espectador à confiança nesse outro criado pelo cinema, passando por muitas dúvidas e risos, por muitas rusgas e preocupações, por muitas trocas de mensagens e aprendizados, as experimentações que vimos realizando no Cineclube Regente/Cha para montar e editar filmes individuais e coletivos mostram que, ao nos deixar levar pelos próprios fragmentos do real capturados nas filmagens, tocamos em muitos elementos presentes num tipo de pedagogia do cinema que nasceu na década de 1920, na distante e não mais existente União Soviética e seguiu se espalhando pelo mundo que ainda existe e está bem próximo de nós.

A montagem, de Eisenstein e Vertov a Godard, rompeu a centralidade do mestre discursivo, apostou na relação entre profundidade e superfície, entre dispersão e atenção, entre força centrípeta e força centrífuga. Com os arquivos, citações, tensões entre imagens, rupturas narrativas, relações dialéticas ou inconclusas, o cinema inventou uma pedagogia (MIGLIORIN; BARROSO, 2019, p. 98).

Ainda que, em filmes distintos, temos experimentado esse tipo de montagem em que a dispersão e a atenção coexistem, em que não mais há a necessidade imperiosa de uma narrativa, nossas 'simples montagens' acabaram por se mostrar como complexidade que nos exige formular conceitos para podermos lidar com nossos próprios processos de aprendizado com e do cinema, para podermos conversar sobre o que temos feito, para podermos escrever o que se passa e tentar convencer o leitor e a leitora de que, pelo menos no lugar-escola onde experimentamos o cinema como arte, não há verdades prontas, há coisas a se inventar. 


\section{Referências}

CAIU O XILOFONE?. Mauro Antonio Guari. 7:42 min. 2020. Disponível em: $<$ https://www.youtube.com/watch?v=AzY1Oh7zV14\&t=181s>. Acesso em: 28 mar. 2020.

CIGARRAS. Direção: Mauro Antonio Guari. 7:02 min. 2019. Disponível em: <https://www.youtube.com/watch?v=0aYosxOhL6g>. Acesso em: 28 mar. 2020.

DELEUZE, G. Proust e os signos. Rio de Janeiro: Forense, 1987.

DELEUZE, G.; GUATTARI, F. Mil Platôs. v. 1. São Paulo: Editora 34, 1997.

DELeUZE, G.; GUATTARI, F. Mil Platôs. v. 4. São Paulo: Editora 34, 1997.

DELIGNY, F. O Aracniano e outros textos. São Paulo: n-1 edições, 2015.

DESGAGNÉ, S. O conceito de pesquisa colaborativa: a idéia de uma aproximação entre pesquisadores universitários e professores práticos. Revista Educação em Questão, Natal, v. 29, n. 15, p. 7-35, maio/ago. 2007

EDGAR-HUNT, R.; MARLAND, J.; RAWLE, S. A linguagem do cinema. Porto Alegre: Bookman, 2013.

ESCÓSSIA, L. da; KASTRUP, V.; PASSOS, Ed. Pistas do Método da Cartografia: pesquisa-intervenção e produção de subjetividade. $v$. 1 . Porto Alegre: Meridional, 2015.

FiOs TrAmAdOs Ao AcAsO. Direção: Sandra Amaral, Rozeli Melo, Wenceslao Oliveira Jr. 9:57 min. 2019 Disponível em: <https://www.youtube.com/watch?v=_0KEVQ8MSF4\&t=1s>. Acesso em: 28 mar. 2020.

GUIMARÃES, C. Cinema de cozinha. Catálogo Mostra Cinema de Cozinha. São Paulo: SESC, 2008.

GUIMARÃES, C. Ver é uma fábula (entrevista). 2013. Disponível em: <https://www.youtube.com/watch?v=n88Ieqcy1Rw>. Acesso em: 01 abr. 2020.

GUSTAVO Entrevista (filme). Direção: Sandra Amaral. Campinas. 2:39 min. 2019. Disponível em: <https://www.youtube.com/watch?v=HgwLHKh9-II>. Acesso em: 28 mar. 2020.

KASTRUP, V. O funcionamento da atenção no trabalho do cartógrafo. In: ESCÓSSIA, L. da; KASTRUP, V.; PASSOS, E. Pistas do método da cartografia: pesquisa-intervenção e produção de subjetividade. Porto Alegre: Sulina, 2009.

MEKAS, J.; MOURÃO, P. Jonas Mekas. São Paulo: Centro Cultural Banco do Brasil; Próreitoria de Cultura e Extensão Universitária - USP, 2013.

MIGLIORIN, C.; BARROSO, E. I. Pedagogias do cinema, montagem. In: MIGLIORIN, C.; PIPANO, I. Cinema de brincar. Belo Horizonte: Relicário, 2019.

MIGLIORIN, C.; PIPANO, I. Cinema de brincar. Belo Horizonte: Relicário, 2019.

MONDZAIN, M.-J. Homo Spectator. Lisboa: Orfeu Negro, 2015. 
O DE Ó eu Mauro. Direção: Mauro Antonio Guari e Sandra Amaral. 2:44 min. 2018. Disponível em: <https://www.youtube.com/watch?v=4w0BEM98Vt4>. Acesso em: 28 mar. 2020.

OLIVEIRA JR, W. M.; AMARAL, S. R. F. Arte e democrazia tra cinema e scuola dell'infanzia. In: INFANTINO, A. (org). I Bambini imparano - il ruolo educativo degli adulti nei servizi per l'infanzia 0-6. Milano: Guerini Scientifica, 2019.

PASSOS, E.; KASTRUP, V. Cartografar é construir um plano comum. Fractal, Rev. Psicol., v. 25, n. 2, p. 263-280, maio/ago. 2013.

PASSOS, E.; KASTRUP, V.; TEDESCO, S. Pistas do Método da Cartografia: a experiência da pesquisa e o plano comum. v. 2. Porto Alegre: Sulina, 2014.

RANCIÈRE, J. O mestre ignorante: cinco lições sobre a emancipação intelectual. Belo Horizonte: Autêntica, 2015.

SOHLEPSE. Direção: Mauro Antonio Guari. Campinas. 1:52 min. 2018. Disponível em: <https://www.youtube.com/watch?v=GLgXcgmZT6g>. Acesso em: 28 mar. 2020.

\footnotetext{
i Professora da Prefeitura Municipal de Campinas - CEI Regente Feijó. Possui graduação em Pedagogia e especialização em Educação Infantil: Alfabetização e Letramento. Integrante do Cineclube Regente/Cha desde 2017 e bolsista do Projeto "Lugar-escola e cinema: afetos e metamorfoses mútuas" [Fapesp 2019/18098-3].

ii Agente de educação infantil da Prefeitura Municipal de Campinas - CEI Cha Il Sun. Possui graduação em Ciências Sociais e especialização em Psicopedagogia Clínica e Educação Infantil. Integrante do Cineclube Regente/Cha desde 2018 e bolsista do Projeto "Lugar-escola e cinema: afetos e metamorfoses mútuas" [Fapesp 2019/18197-1].

iii Professor no Departamento de Educação, Conhecimento, Linguagem e Arte e pesquisador no Laboratório de Estudos Audiovisuais-OLHO, ambos da Faculdade de Educação/Unicamp. Coordenador do Projeto "Lugar-escola e cinema: afetos e metamorfoses mútuas" [Fapesp 2018/09258-4].
}

Como citar esse artigo:

AMARAL, Sandra Regina de Freitas; GUARI, Mauro Antonio; OLIVEIRA JR, Wenceslao Machado. Coisas inventadas: montagem e edição em um cineclube escolar. Revista Digital do LAV, Santa Maria: UFSM, v. 14, n. 1, p. 197-219, jan./abr. 2021. 